\title{
An Investigation on Splat and Flattening Behavior of Thermally Sprayed Copper on A Rough Surface: A New Approach
}

\author{
Satish Tailor · Nitesh Vashishtha · Ankur Modi · S. C. Modi
}

Metallizing Equipment Company Pvt. Ltd. E-101, MIA Phase-II, Basni, Jodhpur, India.

\begin{abstract}
All thermal spray coatings are finally deposited on a rough and active grit-blasted surface of the job. But, available literatures are reporting splat and flattening behavior on a polished surface. There is a gap in thermal spraying to understand actual solidification on a rough surface. Therefore, in the present work an attempt has been made to study of splat formation of thermally sprayed copper onto grit-blasted rough surface. An optimization study is done to collect rounded/semi-rounded disk like splats to set spray parameters. Optimized parameters were also tested at four different gun traverse speeds to fabricate thin Cu coatings $(30-50 \mu \mathrm{m})$.
\end{abstract}

ARTICLE HISTORY

Received 02-01-2020

Revised 11-03-2020

Accepted 13-03-2020

Published 17-03-2020

\section{KEYWORDS}

Thermal Spraying Splat Flattening Behavior

Rough Surface
Thermally spray technology are used to depositing thick coatings (above $50 \mu \mathrm{m}$ ) on a metal, ceramic or fiber substrate of a variety of coating materials. Different types of feedstock such as metals, ceramics, and composites can be used in the form of powder, rod and wire for a wide range of industrial applications and efforts are being made for new applications [1-14]. To understand the deposition process in thermal spraying, there are four steps as shown in Figure 1. In this process, a high temperature flame is produced using either chemical or electrical energy to heat, melt and spray material introduced into the flame. Feedstock injected into the flame is more common in the form of powder but can also be in wire or rod form. Molten droplets are thus transported to an object to produce overlay coatings for protection or performance enhancement purposes $[2,15]$.

As the individual splat is unit cell for the entire coating buildup, the flattening and solidification of the individual particle on the substrate surface is the first fundamental process for the coating fabrication. Coating microstructure and corresponding properties are mainly depends on the flattening nature of each splat and its solidification [1-4]. In general, two typical types of splats, named disk-shaped splat and splash splat, can be obtained on the flat substrate surface under different conditions. Various investigations on splat formation have appeared in the literatures by theoretical, numerical and experimental methods in the past few decades [16-42]. A transition phenomenon in a flattening behavior of the thermal-sprayed particle on the flat substrate surface was introduced by the M. Fukumoto et al. [23, 43-45]. However, these findings are may not be applicable for splat formation in wire-flame spray and arc spray processes because of powder feedstock material was used. There are not enough studies available on splat formation and solidification of thermally sprayed wire feedstock. Study of splat formation and its solidification always is done with a powder feedstock on a polished surface [16-42], but the final coating is deposited on a grit blasted rough surface. However, we still cannot answer why or how does the disk-shaped splat appear, and what is the essential of the splat formation process on a rough surface because of nearly all the previous studies observed the final splats on a polished surface without knowing the actual behavior of splat on a rough surface.

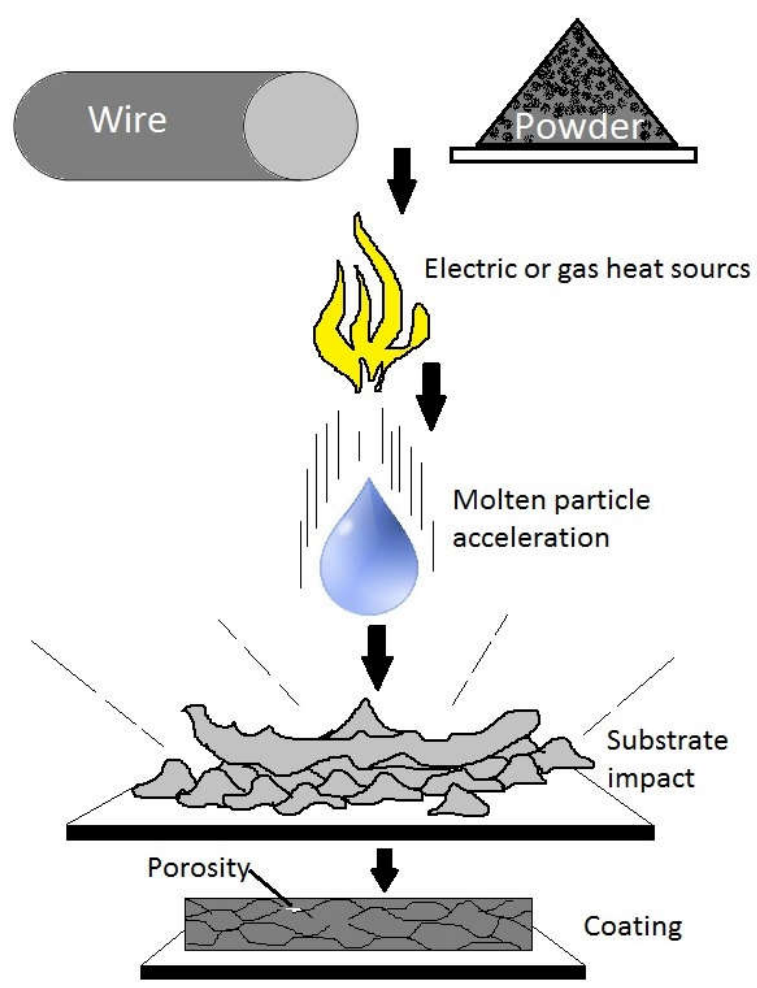

Figure 1: Coating buildup in thermal spray process 

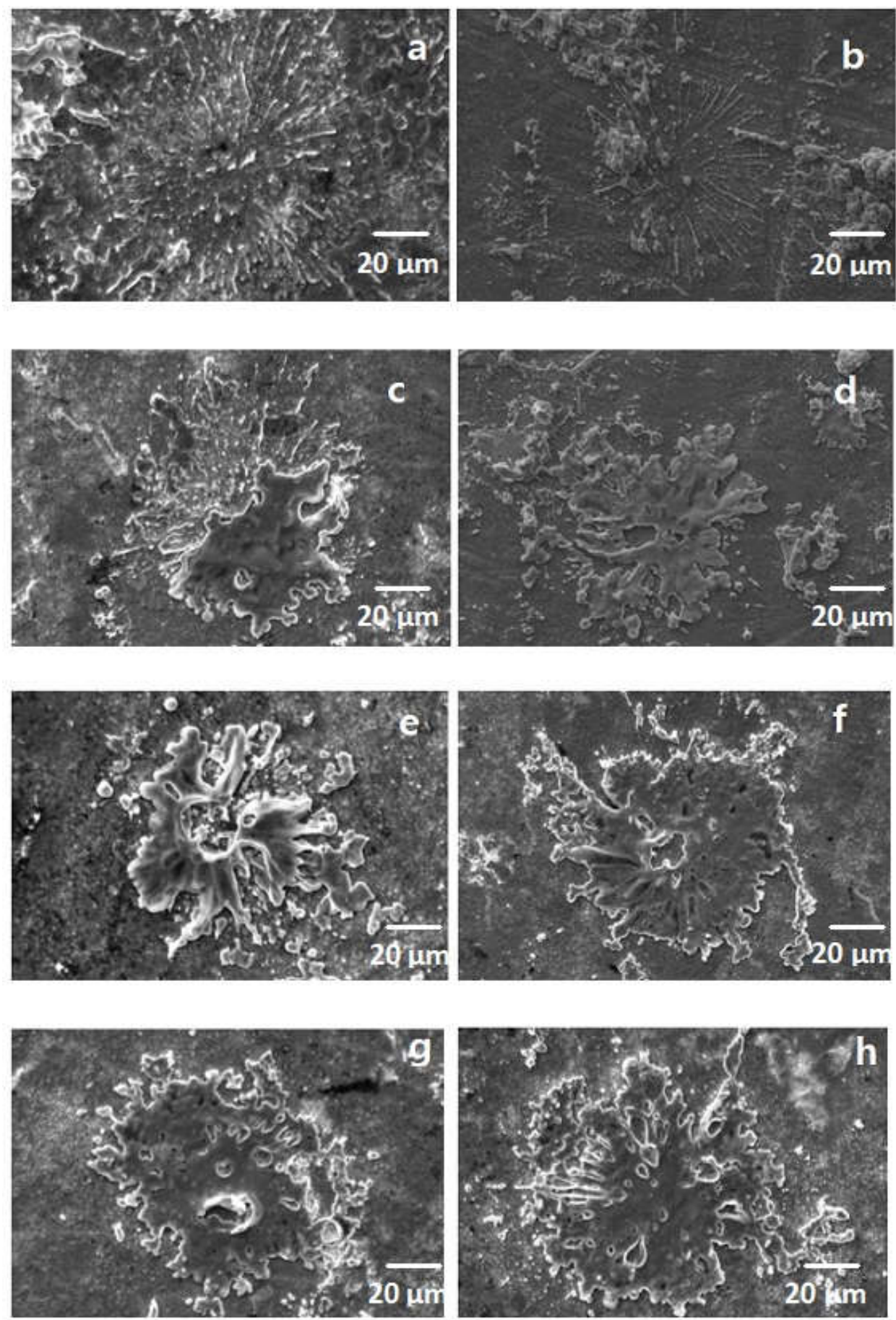

Figure 2: Splash splat formation having different morphologies obtained during the optimization of spray parameters

Therefore, there is a need for a detail study of this aspect using wire feedstock on a grit blasted rough surface. It is necessary to study in detail the basic process of flattening behavior of the sprayed particles on a grit blasted surface, not only from the point of view of scientific interest, but also from that of technical consequences as well. In the present work, an attempt has been made to understand of splat formation and its solidification mechanism of thermally sprayed copper wire onto grit blasted surface of a low carbon steel substrates using newly developed wire based HVOF system (W-HVOF HIJET $9610^{\circledR}$ ).

Copper wire (99.9\% pure) $3.17 \mathrm{~mm}$ in diameter was used as a feedstock material in the preparation of the coating samples. The coatings were deposited onto low carbon steel substrates. Prior to spraying substrate should clean. Substrates were cleaned with acetone for 5 minutes in order to remove any oil marks, pitting and other foreign particles attached with surface and also grit blasted with alumina $\left(\mathrm{Al}_{2} \mathrm{O}_{3}\right)$ in order to increase surface roughness of the surface, in order to improve the adhesion strength of the coating with substrate. After grit blasting, substrates were cleaned with compressed air to remove any grits particles attached on the surface. Substrate roughness was found to be $\mathrm{Ra} \sim 2-2.5 \mu \mathrm{m}$.

$\mathrm{Cu}$-splats were collected on grit blasted substrates using a patented technology (Patent number 214843, Indian Patent 


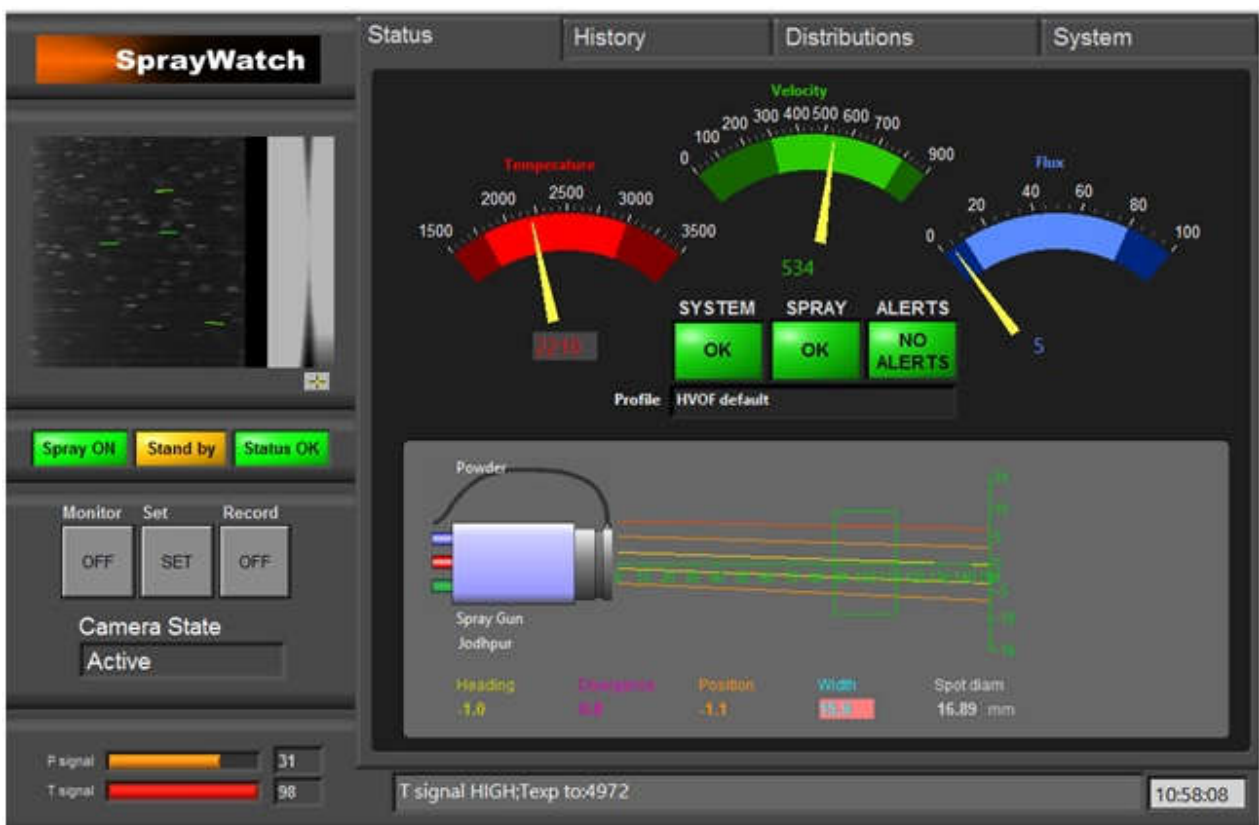

Figure 3: SprayWatch results showing droplet temperature and velocity at optimized spray parameters
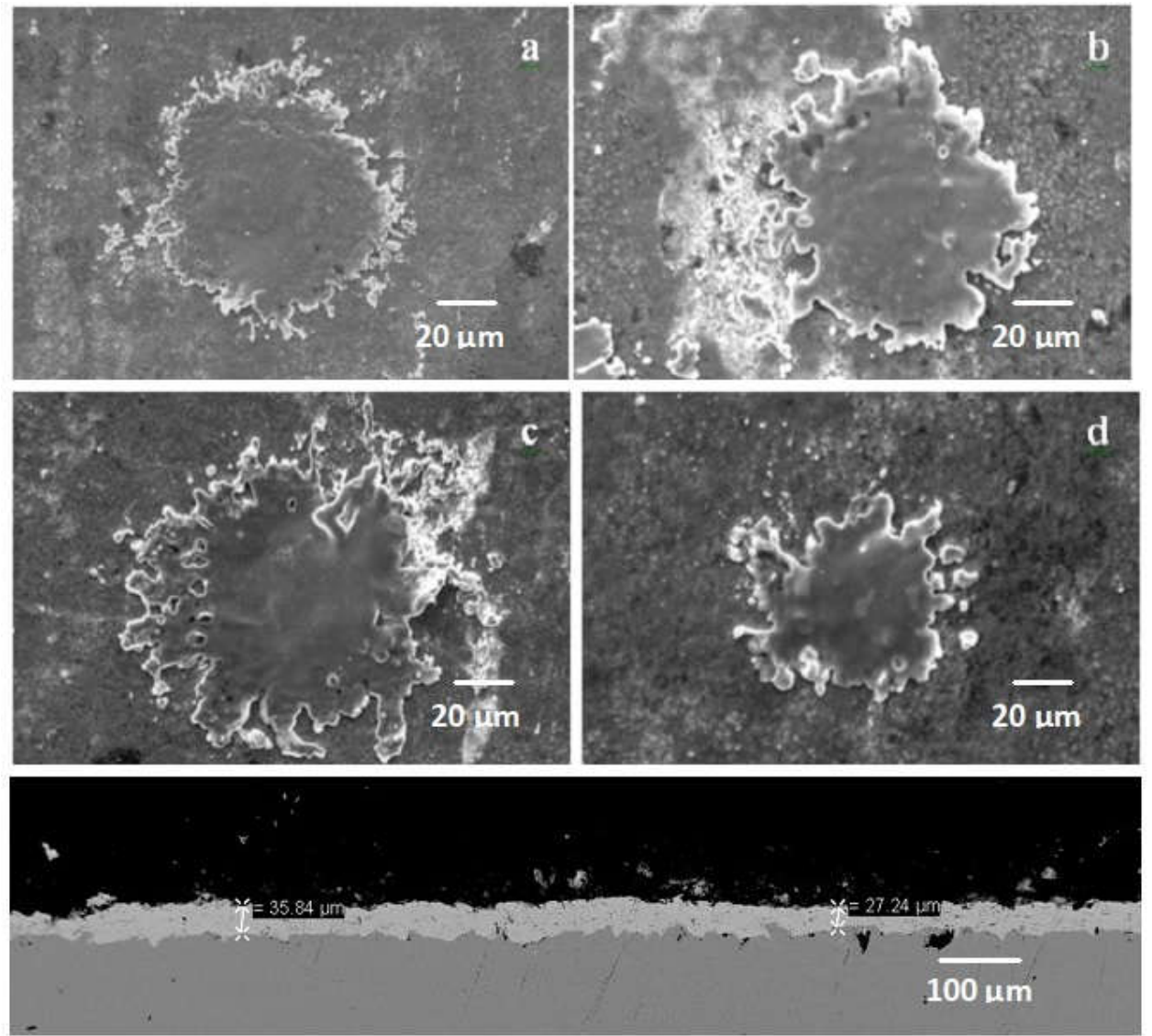

Figure 4: Splat formation at optimized spray parameters at four different gun travel speeds,

(a) $0.30 \mathrm{~m} / \mathrm{s}$, (b) $0.40 \mathrm{~m} / \mathrm{s}$, (c) $0.45 \mathrm{~m} / \mathrm{s}$ and (d) $0.50 \mathrm{~m} / \mathrm{s}$, (e) XRD pattern of as-sprayed thin Cu $0.40 \mathrm{~m} / \mathrm{s}$ speed

application number 2529/DEL/1997) W-HVOF thermal spray system (trade name: HIJET 9610 ${ }^{\circledR}$, Ms. Metallizing Equipment Company Pvt. Ltd. Jodhpur, India). HIJET ${ }^{\circledR}-9610$ is a new technique in itself, which is a combination of arc/flame spray and HVOF thermal spray processes. It deposits porous free, very dense coatings at a very economical cost. This system can deposit thick as well as thin metallic coatings ( $2 \mathrm{~mm}$ maximum and 10 to $40 \mu \mathrm{m}$ minimum) and opens the possibility to use the wires feedstocks in HVOF process, because thermal spray grade powders are very expensive than wires. It could be a promising solution for various industrial applications where only thin coating is required. In W-HVOF process, oxygen-propane or oxygen-liquefied petroleum gas (LPG) can be used as fuel gases. Present study was carried out using oxygen-LPG due to unavailability of propane in India. 
Detailed information about the system and results of deposited coatings can be found elsewhere [5]. Forty experiments were performed using different spray parameters in order to get rounded/semi-rounded splats on rough surface to optimize the processing parameters primarily air flow, spray distance and wire feed rate. Optimized spray parameters are listed in Table 1.

Table 1: Optimized spray parameters for the W-HVOF sprayed Cusplats

\begin{tabular}{cc}
\hline Spray Parameters & Values \\
\hline Oxygen Flow & $230 \mathrm{slpm}$ \\
LPG Flow & $55 \mathrm{slpm}$ \\
Air Flow & $550-650 \mathrm{slpm}$ \\
Spray Distance & $17.78 \mathrm{~cm}$ \\
Wire and size & Copper, $3.17 \mathrm{~mm}$ \\
Wire Feed Rate & $160 \mathrm{~cm} / \mathrm{min}$ \\
\hline Slpm* Standard liter per minute
\end{tabular}

The advancement of the W-HVOF process is that the temperature reaches at the melting point of the wire and due to high velocity, high degree of atomization take place; resulting in, complete melting and there are no unmelted or no semi-molten particles were found in the coatings. Further, to prove this statement, splats were collected on as-blasted rough surface and further studied. By controlling the spraying parameters, mainly the air flow, spray distance and wire feed rate, many types of splats were obtained. During optimizing the air flow, spray distance and wire feed rates were varied in the range of 300-700 slpm, 3-8 inches and $120-170 \mathrm{~cm} / \mathrm{min}$, respectively. The splat flattening behavior reveals that the droplet's kinetic energy and its molten status are critical in determining the splat morphology on a rough surface. It was also noted that the in-flight particle temperature and velocity at the point of impact have a significant effect on the final morphology of the splat. During spray parameters optimization at a higher particle velocity, many types of splash splats were obtained on grit blasted rough surfaces with different morphologies as shown in Fig. 2 (a-h). Due to excess higher particle velocity splash splats with a center splat surrounded by a ring of fragments or numerous splash fingers connect with the central solidification core were formed as shown in Fig. 2 (a-c). After controlling the spray parameters semi-disk-shaped splats were obtained, but not fully rounded and also having pores after the solidification as shown in Fig. $\mathbf{2}$ (d-h), which leads porosity in the coating.

After forty numbers of experiments, fully melted semirounded disk-shaped splats with only a regular central disk were obtained on the grit blasted substrate surface under designated conditions. These spray parameters (Table 1) were identified as optimized spray parameters to deposit coatings. At these optimized spray parameters, droplet velocity and temperature were measured by SprayWatch (Fig. 3) and found to be $534 \mathrm{~m} / \mathrm{s}$ and $2210^{\circ} \mathrm{C}$, respectively. These optimized spray parameters were also tested for four different traverse speeds at $0.30 \mathrm{~m} / \mathrm{s}, 0.40 \mathrm{~m} / \mathrm{s}, 0.45$ $\mathrm{m} / \mathrm{s}$ and $0.50 \mathrm{~m} / \mathrm{s}$, in order to investigate the splat formation mechanism at different traverse speed on a rough surface. Substrate temperature was maintained in between $30-50^{\circ} \mathrm{C}$ by compressed air jet. From the Fig. 4 (a-d), it can be seen that all four different gun travel speeds, fully melted semi-rounded disk-shaped splats were obtained.
No oxide contents were found in the XRD analysis. However, in thermal spraying generally, oxides are formed. In EDS analysis of Cu-splat, it was found that Oxygen content is very low that its peak does not appear in the results. Thus, it means high particle velocity $(534 \mathrm{~m} / \mathrm{s})$ in the W-HVOF prevents oxide formation during the spraying. In the W-HVOF flame is reducing in nature, it means that supplied oxygen gas was fully consumed to build a proper flame. Further, it can be attributed to the fact that due to it is lacking oxygen in the flame retardant and a shorter dwelling of particles within the flame reduces in-flight oxidative processes. Controlling oxide formation in the thermal spraying process is the advantage of this W-HVOF system. Its well known that oxidation in the coating alters its electrical properties.

After splat optimization study, a thin metallic coating less than $50 \mu \mathrm{m}$ was deposited on the low carbon steel substrate in order to investigate the coating microstructure and its mechanical properties. Figure $4 \mathbf{e}$ shows the crosssection of as-sprayed thin copper coatings. A very dense and micro-cracks free microstructures can be seen. Porosity in the coating found to be $1-2 \%$. Bend test was performed as per ASTM E290-14 to check delamination characteristics of the thin $\mathrm{Cu}$ coating and it was considered as a test to check the adhesion strength of the thin coatings. Strip bend test of the thin $\mathrm{Cu}$ coating shows that generated cracks are minor and acceptable. The adhesion strength of the coating was tested using a portable PosiTest pull-off adhesion tester as per per ASTM-D4541, D7234, ISO 4624. The specimens were directly adhesive-bonded onto the $\mathrm{Cu}$ coated substrate. The adhesion strength of thin $\mathrm{Cu}$ coatings was found to be $20 \mathrm{Mpa}$, which is good for thermal sprayed thin coating. Thin copper coating's other mechanical and electrical properties have been reported elsewhere [4647].

In summary, splat formation and its flattening behavior of thermally sprayed metal wires have not been studied in details so far. Therefore, in the present work splat formation and flattening behavior of thermally sprayed $\mathrm{Cu}$ wire have been investigated on a rough surface. Cu-splats were collected onto a grit blasted low carbon steel substrate by using newly developed W-HVOF process (HIJET 9610 ${ }^{\circledR}$ ). After optimization study spray parameters were set to achieve semi-rounded disk like splats. Results show that no cracks were observed in the splat after solidification, complete melting take place and there are no unmelted particles were found. Furthermore, thin coating properties were tested. A uniform thin $\mathrm{Cu}$ coating $(\sim 35$ $\mu \mathrm{m})$ was successfully deposited. Porosity in the coating is found to be $2-3 \%$, adhesion strength of thin $\mathrm{Cu}$ coating is found to be $20 \mathrm{Mpa}$. In addition, bend test showed good coating bonding with the substrate.

\section{References}

1. Satish Tailor, V. K. Sharma, P. R. Soni, Plasma Spray Coatings: State Of The Art, Transaction of PMAI, 2010, 36, 127-131.

2. Satish Tailor, Development and Characterization of Plasma Sprayed Aluminum Based Nano Composite Coatings, PhD thesis (2013), MNIT Jaipur.

3. P. Fauchais, M. Fukumoto, A. Vardelle, M. Vardelle, Knowledge Concerning Splat Formation: An Invited Review, Journal of Thermal Spray Technology, 2004, 13(3), 337-360.

4. M. Fukumoto, H. Hayashi, T. Yokoyama, J. Jpn Therm. Spray Soc. 1995, 32(3), 1498. (in Japanese) 
5. Satish Tailor, Ankur Modi, S.C. Modi, High-Performance Molybdenum Coating by Wire-HVOF Thermal Spray Process, Journal of Thermal Spray Technology, 2018, 27, 757-768.

6. Satish Tailor, Pranay A Bagde, Sanjay Sapate et al., Friction and Wear Behaviour of Plasma Sprayed Cr203-Ti02 Coating, Materials Research Express, 2018, 5, 1-14.

7. Satish Tailor, Ankur Modi, S.C. Modi, Effect of controlled segmentation on the thermal cycling behavior of plasma sprayed YSZ thick coatings, Ceramics International, 2018, 44(6), 6762-6768.

8. Satish Tailor, et al., Atmospheric plasma sprayed 7\%-YSZ thick thermal barrier coatings with controlled segmentation crack densities and its thermal cycling behavior, Ceramics International, 2018, 44(3), 2691-2699.

9. Satish Tailor et al., High performance thermal-sprayed WC$10 \mathrm{Co}-4 \mathrm{Cr}$ coatings in narrow and complex areas, Surface Engineering, 2018, 34 (5), 412-421.

10. R. A. Miller, Current status of thermal barrier coatings-an overview, Surface and Coatings Technology, 1987, 30, 1-11.

11. G. Barbezat, Advanced thermal spray technology and coating for lightweight engine blocks for the automotive industry, Surface and Coatings Technology, 2005, 200(5-6), 19901993.

12. J. Matějíček, P. Chráska, J. Linke, Thermal spray coatings for fusion applications-review, Journal of Thermal Spray Technology, 2007, 16(1), 64-83.

13. M. L.Thorpe, Thermal spray. Industry in transition, Advanced Materials and Processes, 1993, 143(5), 50-61.

14. F. Kassabji, G. Jacq, J. P. Durand, Thermal spray application for the next millennium a business development perspective, in Proceedings of the 15th International Thermal Spray Conference, 1998, 1677-1680.

15. L. Pawlowski, The Science and Engineering of Thermal Spray Coatings, John Wiley\& Sons, New York, I995.

16. J. Madjeski, Solidification of droplets on a cold surface, 1976, Int. J. Heat Mass Transfer, 19(9), 1009-1013.

17. H. Fukanuma, A porosity formation and flattening model of an impinging molten particle in thermal spray coatingsJ. Therm. Spray Technol., 1994, 3 (1), 33-44.

18. A.T.T. Tran, S. Brossard, M.M. Hyland, B.J. James, P. Munroe, Evidence of Substrate Melting of NiCr Particles on Stainless Steel Substrate by Experimental Observation and Simulations, Plasma Chem. Plasma Process., 2009, 29, 475.

19. G. Montavon, S. Sampath, C.C. Berndt, H. Herman, C. Coddet, Effect of vacuum plasma spray parameters on splat morphology, J. Therm. Spray Technol., 1995, 4, 67-74.

20. C.J. Li, J.L. Li, W.B. Wang, A. Ohmori, K. Tani, in: C. Coddet (Ed.), Proceedings of the International Thermal Spraying Conference, Pub. ASM International, Materials Park, $\mathrm{OH}$, USA, 1998, 481.

21. C. Moreau, P. Gougeon, M. Lamontagne, Influence of Substrate Preparation on the Flattening and Cooling of Plasma-Sprayed Particles, 1995, J. Therm. Spray Technol. 4, 25-33.

22. V. Pershin, M. Lufitha, S. Chandra, J. Mostaghimi, Effect of substrate temperature on adhesion strength of plasmasprayed nickel coatings, 2003, J. Therm. Spray Technol., 12 (3), 370-376.

23. A. McDonald, C. Moreau, S. Chandra, Effect of substrate oxidation on spreading of plasma-sprayed nickel on stainless steel, Surf. Coat. Technol., 2007, 202, 23-33.

24. M. Ducos, J. P. Durand, Thermal coatings in Europe: a business prospective, in Proceedings of the International Thermal Spray Conferences, 2001, 1267-1271.

25. M. Fukumoto, S. Y. Hwang, C. J. Li, K. Tani A, Nakahira, M. K. A. Khor, The current status of thermal spraying in Asia, Journal of Thermal Spray Technology, 2008, 17(1), 5-13.

26. M. Fukumoto, H. Hayashi, T. Yokoyama, Relationship between particle's splat pattern and coating adhesive strength of HVOF sprayed Cu-alloy, Journal of Japan Thermal Spraying Society, 1995, 2(3), 149-156.

27. M. Ivosevic, V. Gupta, J. A. Baldoni, R. A. Cairncross, T. E. Twardowski, R. Knight, Effect of substrate roughness on splatting behavior of HVOF sprayed polymer particles: modeling and experiments, Journal of thermal Spray Technology, 2006, 15(4), 725-730.

28. S. Brossard, Paul Munroe, Margaret Hyland, Study of the Splat Formation for HVOF Sprayed $\mathrm{NiCr}$ on Stainless Steel Substrates and the Effects of Heating and Boiling PreTreatments, Journal of Thermal Spray Technology, 2010, 19(5), 990-1000

29. S. Brossard, Paul Munroe, Margaret Hyland, Microstructural Study of Splat Formation for HVOF Sprayed NiCr on PreTreated Aluminum Substrates, Journal of Thermal Spray Technology, 2010, 19(5),1001-1012.

30. Li, Guang-Rong; Lv, Bo-Wen; Yang, Guan-Jun; Zhang, Wei-Xu; Li, Cheng-Xin; Li, Chang-Jiu, Relationship Between Lamellar Structure and Elastic Modulus of Thermally Sprayed Thermal Barrier Coatings with Intra-splat Cracks, Journal of Thermal Spray Technology, 2015, 24(8), 1355-1367.

31. M. Fukumoto, M. Shiiba, H. Kaji, T. Yasui, Three dimensional transition map of flattening behavior in the thermal spray process, Pure and Applied Chemistry, 2005, 77(2), 429-442.

32. M. Fukumoto, K. Yang, M. Yamada, T. Yasui, Splat formation mechanism in thermal spraying, Journal of Solid Mechanics and Material Engineering, 2011, 5(12), 1001-1014.

33. M. Fukumoto, K. Yang, K. Tanaka, T. Usami, T. Yasui, M. Yamada, Effect of substrate temperature and ambient pressure on heat transfer at interface between molten droplet and substrate surface, Journal of Thermal Spray Technology, 2011, 20(1-2), 48-58.

34. M. Vardelle, A. Vardelle, A. C. Leger, P. Fauchais, D. Gobin, Influence of particle parameters at impact on splat formation and solidification in plasma spraying processes, Journal of Thermal Spray Technology, 1995, 4(1), 50-58.

35. Cedelle, M. Vardelle, P. Fauchais, Influence of stainless steel substrate preheating on surface topography and on millimeter- and micrometer-sized splat formation, Surface and Coatings Technology, 2006, 201(3-4), 1373-1382.

36. A. McDonald, C. Moreau, S. Chandra, Thermal contact resistance between plasma-sprayed particles and flat surfaces, International Journal of Heat and Mass Transfer, 2007, 50(9-10), 1737-1749.

37. R. Dhiman, A. G. McDonald, S. Chandra, Predicting splat morphology in a thermal spray process, Surface and Coatings Technology, 2007, 201(18), 7789-7801.

38. D. K. Christoulis, D. I. Pantelis, N. de Dave-Fabrègue, F. Borit, V. Guipont, M. Jeandin, Effect of substrate temperature and roughness on the solidification of copper plasma sprayed droplets, Materials Science and Engineering A, 2008, 485(12), 119-129.

39. K. Yang, K. Tanaka, T. Usami, M. Fukumoto, Role of ambient pressure on splat formation and coating adhesion strength during thermal spraying process, Quarterly Journal of the Japan Welding Society, 2011, 29(3), 151-155.

40. K. Yang, Y. Ebisuno, K. Tanaka, M. Fukumoto, T. Yasui, M. Yamada, Verification of the flattening behavior of thermal sprayed particles and free-falling droplets through controlling ambient pressure, Surface and Coatings Technology, 2011, 205(13-14), 3816-3823.

41. S. Brossard, P. R. Munroe, A. T. T. Tran, M. M. Hyland, Study of the effects of surface chemistry on splat formation for plasma sprayed $\mathrm{NiCr}$ onto stainless steel substrates, Surface and Coatings Technology, 2010, 204(9-10), 1599-1607.

42. S. Chandra, P. Fauchais, Formation of solid splats during thermal spray deposition, Journal of Thermal Spray Technology, 2009, 18(2), 148-180.

43. K. Yang, K. Tomita, M. Fukumoto, M. Yamada, and T. Yasui, Effect of Ambient Pressure on Flattening Behavior of Thermal Sprayed Particles, J. Therm. Spray Technol., 2009, 18(4), 510-518.

44. M. Fukumoto, T. Yamaguchi, M. Yamada, and T. Yasui (2007) Splash Splat to Disk Splat Transition Behavior in PlasmaSprayed Metallic Materials, J. Therm. Spray Technol. 16(56):905-912.

45. S. Sampath, H. Herman, Rapid solidification and microstructure development during plasma spray deposition, J. Therm. Spray Technol. 1996, 5 (4), 445-456. 
46. Satish Tailor, Ankur Modi, S.C. Modi, Development of thermal sprayed thin copper coatings, Proceedings of ITSC2018, ASM Intr., 2018, 811-817.

47. Satish Tailor, Ankur Modi, S.C. Modi, Thermally sprayed thin copper coatings by W-HVOF, Journal of Thermal Spray Technology, 2019, 28 (1-2), 273-282.

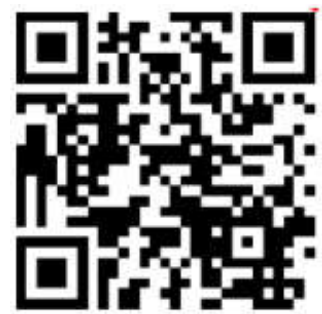

